\title{
Should We Write Prenuptial Contracts?
}

\author{
Helmut Rainer*† \\ The University of Essex
}

August 10, 2004

\begin{abstract}
A successful marriage requires for both parties to make investments in their relationship and marital assets. How such assets would be divided if and when the parties divorce is an important factor determining each party's (exante) investment incentives. Using the "incomplete contracting" approach, we characterize the optimal asset division rule, one that provides the parties with the best investment incentives. We then discuss the circumstances under which the spouses would agree, in equilibrium, to write a prenuptial contract with this asset division rule. We conclude by exploring the implications of our results in the context of various asset division rules currently discussed by policy-makers.
\end{abstract}

Keywords: Asset Division, Terms of Divorce, Marriage Contracts, Marital Investments and Negotiations.

JEL Classification Numbers: J12, K11, D78

*Address for Correspondence: Department of Economics, University of Essex, Wivenhoe Park, Colchester CO4 3SQ, United Kingdom. E-mail: hraine@essex.ac.uk.

${ }^{\dagger}$ For helpful comments by Abhinay Muthoo, Marco Francesconi, Saku Aura, Venkataraman Bhaskar, Marco Mariotti, Stephen McKnight, the seminar participants at University of Essex, Birmingham University, and Queen Mary, University of London, I am grateful. I would also like to express my thanks to the editor, Esther Gal-Or, the Associate Editor and two referees for their detailed and helpful comments and suggestions. 
"Ends may influence beginnings. In a society where one-half of all new marriages are expected to end in divorce, a radical change in the rules for ending marriage inevitably affects the rules for marriage itself and the intentions and expectations of those who enter it." Leonore Weitzman (1985)

"Marriage is the most important contract, for ourselves and for the wider world, that most of us will make, yet men and women sign up to it on an erotic high without mentioning the terms of the contract, still less examining them." The Sunday Times (July 11, 2004)

\section{INTRODUCTION}

When a marriage dissolves, a couple usually divides all marital assets according to the division rule imposed upon them by the state. However, growth in asset ownership and marital breakdown has increased demand by married couples to contract out state-imposed rules governing the allocation of marital assets upon divorce. Pre-marital contracting in Europe is particularly notable in the Netherlands, where prenuptial agreements are reported to be signed before 25 percent of all marriages (Smith, 2003). In Norway, contracts are also available to cohabitants. While less than 20 percent of all cohabitants had signed a contract in 1997, this proportion was close to 40 percent for cohabiting individuals aged fifty or over (Noack, 2001). In the United States, approximately 5 percent of marrying couples are reported to have signed prenuptials, with that number rising to an estimated 20 percent for remarrying couples (Marston, 1997).

In spite of the increased practical relevance of prenuptial agreements in Europe and elsewhere, there is still much debate about their role. Advocates of prenuptial agreements see their advantages in terms of the benefits of certainty and contractual autonomy in the context of heterogenous marital circumstances. Critics suggest that prenuptial agreements may increase - rather than decrease - the likelihood of divorce by requiring couples to consider explicitly the terms of a divorce settlement. Moreover, initiating a prenuptial bargain may send a negative signal that the initiators expectation of divorce is high (Spier, 1992). The main objection against prenuptial agreements is the allegation that in a society where 'power' is systematically distributed asymmetrically, marriage contracts are likely to reinforce such an asymmetry (McLellan, 1996). In other words, prenuptial contracts may overwhelmingly hurt one party in the event of a divorce by virtue of his or her inferior bargaining power at the time of contract-bargaining.

To assess these debates requires an understanding of why a contract that departs significantly from the state-imposed division rules may be jointly preferred by a couple entering into a marriage relationship. In other words, it is necessary to identify the source of failure of state-imposed divorce laws that prenuptial agreements will remedy. This paper puts forward a case for marriage contracts, arguing that greater investments in relationship-specific assets would be made as a result.

To analyze this issue we develop a model of marriage in which a married (or cohabiting) couple makes three decisions. In the first stage, the two partners deter- 
mine and negotiate the terms of divorce and stipulate them in a contract in which they agree on the division of the marital assets upon divorce. In the second stage, each partner undertakes a relationship-specific investment that enhances the value of the said assets. ${ }^{1}$ Finally, in the third stage, the couple bargain over the partition of the marital surplus generated from their investments in the shadow of divorce.

A key feature of the model is that the partners are unable to contract upon the investments they make in the assets (due to various factors such as that such investments are not verifiable by "third parties"). The investments that we have in mind may also be multidimensional in nature. They may not just be dollar amounts (e.g., cost of renovations), but also stand for decisions to exert effort towards the household's assets (e.g., DIY, maintenance), and contributions made by each spouse towards the acquisition of the family asset by performing domestic duties, thereby releasing their partners for gainful employment. Since these investments are not part of any marital contract, there remains scope for the couple to bargain ex post over the division of the surplus generated from their investments. The terms of divorce determine the parties' outside option payoffs. Therefore, they will have an impact on the relative bargaining powers of the partners within marriage, and hence affect the distribution of the marital surplus. This, in turn, influences the partners' marginal returns on investments, and thus their incentives to invest in the relationship in the first place. Hence the terms of divorce may have efficiency consequences as well as having distributive consequences.

Our analysis highlights that the various asset division regimes currently discussed by policy-makers (which we refer to in more detail below) would in general lead to inefficient investments in marital specific assets. Precisely because this underinvestment would reduce the gains from marriage, we model the terms of divorce as being decided at the outset of marriage, as part of an ex ante "separation" agreement that stipulates the division of marital assets in the event of a divorce. We obtain three main sets of results.

First, we derive and study the optimal asset division rule, one that maximizes the actual gains from marriage. Two sets of parameters in our model are central to the determination of the optimal division rule. The first is given by the preference parameters that capture the partners' respective valuations of the household asset in both marital states (i.e, 'married' and 'divorced'). The second set is represented by the technological parameters that capture the productivities of each partner's relationship-specific investment. In general, the optimal division rule is a non-trivial function of both preference and technology parameters. We show that, in a broad range of cases, the spouse that has a higher valuation of the household asset in

\footnotetext{
${ }^{1}$ Our analysis is carried out as though investments enhance the marketable value of the marital assets. As we explain below, such investments may involve time, effort, and financial inputs. Yet, in practice, there are other important aspects of marital investments not dealt with here. For example, some spouse may sacrifice himself or herself to enhance the "entire value of marriage" (i.e., the utility derived from being a happy family) which will be sustained and consumed only if the relationship remains intact, whereas if it does not work out then the value generated from this investment dissappears and hence does not have a market (or "salvage") value.
} 
the divorce state should optimally have a smaller share of the couple's assets. This proposition leads to a key insight, namely that the optimal allocation of property rights over marital assets should be governed by the principle to equalize the parties' bargaining powers within marriage in order to counter rent-seeking opportunism. This is consistent with the aim of inducing both parties to provide the optimal level of relationship-specific investment.

Second, we address the question of whether, or under what circumstances, will two partners agree in equilibrium to write a prenuptial contract with the optimal asset division rule. In doing so, we consider an environment in which laws governing the division of assets on divorce set the default rules within the shadow of which a prenuptial contract may (or may not) emerge. A key insight we obtain is that, for any given couple, the incentive to write a prenuptial contract is a function of these rules. In particular, we show that the greater the "difference" between the optimal asset division rule and the default rule, the more likely it is that prenuptial contracts will be agreed upon. Moreover, we show that some degree of heterogeneity in the partners' preferences is conducive for an inefficient default rule to be replaced by a negotiated asset division rule.

Finally, we apply our results to evaluate various currently used default asset division rules. Such division rules include $(i)$ the 'equal division of property'; $(i i)$ the 'compensation approach'; and (iii) the 'needs approach' (see Tee 2001). Our findings suggest that each of these devices may have drawbacks: because different legal rules give various amounts of bargaining "chips" to the spouses, changing the standard would affect each party's bargaining strength and would therefore distort decisions and outcomes within marriage away from the first-best. Assessing the incentive effect of each approach, two robust results emerge. First, we show that the increasing opportunities of women outside marriage, which can be seen as an indication of women's greater bargaining power within it, should be accompanied by the demise of female presumption in property disputes and by legal changes towards "equal splits" in divorce settlements. Second, when women almost entirely specialize in domestic work, and as a consequence have low bargaining powers, then divorce settlements should favor female partners, thereby leaving them one instrument of power which they have not signed away.

Our analysis builds upon the property rights approach as pioneered by Grossman and Hart (1986) and Hart and Moore $(1990)^{2}$, but it is also related to the increasing number of studies that explore the implications of the inability of household members to "commit across time" - inability which typically leads to inefficient household resource allocations. Recent family models which have the feature of constraint efficiency include Konrad and Lommerud (2000), Lundberg and Pollak (2001), and Rasul (2001). ${ }^{3}$ The paper closest in spirit to ours is Aura (2003), who

\footnotetext{
${ }^{2}$ See de Meza and Lockwood (1998), Rajan and Zingales (1998), Nöldeke and Schmidt (2000), and Besley and Ghatak (2001) for recent contributions that extend their work.

${ }^{3}$ For a comprehensive survey of the relevant work in this area see Lundberg (2002).
} 
studies how divorce rules can have an effect on savings for intact families. ${ }^{4}$ The common feature of these models is that they set aside the ruling tradition in family economics that households are able to reach efficient outcomes. ${ }^{5}$

The remainder of this paper is organized as follows. In the following section, we lay out the model. The main results are presented and discussed in Section 3. In Section 4, we consider an applications of our analysis, with special emphasis on the ongoing discussion among policy makers as to appropriate role and extent of the marital property laws. Section 5 concludes. All technical proofs are relegated to the Appendix.

\section{The Model}

2.1. The Framework. There are two family members, a husband $h$ and a wife $w$. The two partners interact over three "dates". At DATE 1, the couple determine how a single family asset is to be split if they divorce each other at date $3 .{ }^{6}$ Denote by $\pi(\pi \in[0,1])$ the share of the asset that goes to $h$; hence $1-\pi$ denotes $w$ 's share. At DATE 2, each agent simultaneously and noncooperatively undertakes an investment which enhances the value of the said asset. Let $I_{h} \geq 0$ and $I_{w} \geq 0$ denote the level of the investments undertaken, where the cost of investing $I_{i}$ is $I_{i}$. The investments are "sunk" once they have been made, and are entirely embodied in the household asset. The value of the asset depends on the investment levels and is denoted $V\left(I_{h}, I_{w}\right)$. We assume that $V\left(I_{h}, I_{w}\right)$ is strictly increasing in each of its arguments, strictly concave, smooth, and satisfies the Inada endpoint conditions. At DATE 3, the couple bargain over whether or not to continue to remain married and over the partition of the marital surplus generated from their investments. We use the Nash bargaining solution to describe the outcome of these negotiations.

The utility payoffs to $h$ and $w$ if they negotiate an agreement at date 3 over the division of the marital surplus are respectively

$$
u_{h}=\gamma_{h} V\left(I_{h}, I_{w}\right)-T \text { and } u_{w}=\gamma_{w} V\left(I_{h}, I_{w}\right)+T
$$

where $T$ denotes an inter-spousal transfer of utility, which can be positive (if the transfer is from $h$ to $w$ ) or negative (if the opposite is true). The parameter $\gamma_{i}>0$ is a preference parameter that captures the degree/extent to which party $i(i=h, w)$ derives utility from the household asset in the regime (or state) in which couples are (happily) married.

\footnotetext{
${ }^{4}$ Relatedly, Rasul (2003) and Francesconi and Muthoo (2004) also apply the incompletecontract approach to the allocation of property rights to consider how custodial rights matter for investments in child quality.

${ }^{5}$ For example, the "unitary approach" (Becker, 1991), the "collective approach" (Chiappori 1992; Chiappori, Fortin, and Lacroix 2002) and Nash bargaining models of the family (Manser and Brown 1980; McElroy and Horney 1981) work with the assumption that families are able to reach efficient outcomes.

${ }^{6}$ The procedure through which this is done is discussed in section 3 .
} 
The payoffs to the husband and the wife respectively from divorce are

$$
\begin{gathered}
d_{h}=\mu_{h} \pi V\left(I_{h}, I_{w}\right), \\
d_{w}=\mu_{w}(1-\pi) V\left(I_{h}, I_{w}\right),
\end{gathered}
$$

where $\mu_{i}>0$ denotes the degree to which party $i$ derives utility from the asset in the regime in which couples are divorced. We assume that the degree to which each party derives utility from the household asset is higher in the married state than in the divorce state, i.e.:

Assumption 1. $\gamma_{i} \geq \mu_{i}$ for each $i=h, w$.

It is assumed that the above three-stage game is one with complete information. In particular, the values of all the parameters (such as each party's preference parameters) are common knowledge between the two spouses. We now characterize the unique subgame-perfect equilibrium (SPE) of our three-stage game using the backwards induction procedure.

2.2. The Bargaining Outcome. Suppose that, at date 1, the spouses negotiate a pre-nuptial contract that specifies an allocation of property rights over the household asset upon divorce, as captured by an arbitrary value of $\pi$. And furthermore, let $\left(I_{h}, I_{w}\right)$ denote an arbitrary pair of investments undertaken at date 2 . Then, since (by Assumption 1)

$$
\left(\gamma_{h}+\gamma_{w}\right) V\left(I_{h}, I_{w}\right)>\left[\mu_{h} \pi+\mu_{w}(1-\pi)\right] V\left(I_{h}, I_{w}\right),
$$

a marital surplus exists at date 3 . Hence, at date 3 , it is mutually beneficial (Paretoefficient) for the couple to agree to remain married and strike an agreement on how to allocate the marital surplus. ${ }^{7}$ Applying the Nash Bargaining solution with the divorce payoffs as the threat point, it is easy to show that the Nash bargained payoff to party $i(i=h, w)$ is:

$$
\begin{gathered}
u_{i}^{N}=\theta_{i} V\left(I_{i}, I_{j}\right), \quad \text { where } \\
\theta_{h}=\left[\frac{\gamma_{h}+\gamma_{w}+\mu_{h} \pi-\mu_{w}(1-\pi)}{2}\right], \quad \text { and } \\
\theta_{w}=\left[\frac{\gamma_{h}+\gamma_{w}-\mu_{h} \pi+\mu_{w}(1-\pi)}{2}\right] .
\end{gathered}
$$

Notice that $i$ 's $(i=h, w)$ payoff is a fraction $\theta_{i} /\left(\gamma_{h}+\gamma_{w}\right)$ of the gross marital surplus $\left(\gamma_{h}+\gamma_{w}\right) V\left(I_{h}, I_{w}\right)$. Thus, $\theta_{i}$ defines $i$ 's bargaining power. Notice that the husbands's bargaining power $\theta_{h}$ is increasing in $\pi$, while the wife's bargaining powers $\theta_{w}$ is decreasing in $\pi$.

\footnotetext{
${ }^{7}$ Because the divorce payoffs are not affected by exogenous shocks, divorce is ruled out in equilibrium. However, our main point that the allocation of marital property rights on divorce can have incentive effects by influencing intra-household power relations remains valid even in the presence of divorce occuring on the equilibrium path.
} 
2.3. Equilibrium Investments. The FIRST-BEST levels of investments $\left(I_{h}^{E}, I_{w}^{E}\right)$ maximize aggregate marital net surplus:

$$
\left(I_{h}^{E}, I_{w}^{E}\right) \in \arg \max _{I_{h}, I_{w}} S \equiv\left(\gamma_{h}+\gamma_{w}\right) V\left(I_{h}, I_{w}\right)-I_{h}-I_{w} .
$$

Thus, the first-best investment levels $I_{h}^{E}$ and $I_{w}^{E}$ are the unique solutions to the first order conditions

$$
\begin{aligned}
& \left(\gamma_{h}+\gamma_{w}\right) V_{h}\left(I_{h}, I_{w}\right)=1 \\
& \left(\gamma_{h}+\gamma_{w}\right) V_{w}\left(I_{h}, I_{w}\right)=1
\end{aligned}
$$

where $V_{i}$ is the first-order derivative with respect to $I_{i}(i=h, w)$. The left-hand sides in (8) and (9) represent the parties' respective social marginal returns from investing, while the right-hand sides the private marginal costs.

The EQUILIBRIUM investments $I_{h}$ and $I_{w}$ are chosen at date 2 to maximize $u_{h}^{N}-I_{h}$ and $u_{w}^{N}-I_{w}$, respectively. We denote the Nash equilibrium investments chosen by $h$ and $w$ by $I_{h}^{*}$ and $I_{w}^{*}$, respectively. Given our assumptions, $\left(I_{h}^{*}, I_{w}^{*}\right)$ are the unique solution to the following first-order conditions:

$$
\begin{aligned}
\theta_{h} V_{h}\left(I_{h}, I_{w}\right) & =1, \\
\theta_{w} V_{w}\left(I_{h}, I_{w}\right) & =1 .
\end{aligned}
$$

Notice that (since $\theta_{i}$ depends on $\pi$ ) $I_{i}^{*}$ depends on the allocation of property rights, $\pi$, which is determined at date 1 . The left-hand sides in (10) and (11) represent the private marginal returns from investing, while the right-hand sides are the private marginal costs. Since the private marginal benefits of an investment in (10) and (11) are less than the social marginal benefits in (8) and (9), it thus follows that each player underinvests relative to the first-best:

Lemma 1 The equilibrium investment levels are strictly less than the corresponding first-best investment levels.

Since $I_{h}^{*}$ and $I_{w}^{*}$ depend on $\pi$, it is clear that in general $\pi$ will be crucial in determining the size and direction of the investment distortions. To investigate exactly how $\pi$ matters, we totally differentiate (10) and (11) with respect to $\pi$ and find that

$$
\begin{aligned}
& \frac{\partial I_{h}^{*}}{\partial \pi}=\frac{1}{\Delta}\left[\frac{\partial \theta_{h}}{\partial \pi}\left(-\frac{V_{h w} V_{w}}{\theta_{w}}-\frac{V_{w w} V_{h}}{\theta_{h}}\right)\right] \text { and } \\
& \frac{\partial I_{w}^{*}}{\partial \pi}=\frac{1}{\Delta}\left[\frac{\partial \theta_{w}}{\partial \pi}\left(-\frac{V_{w h} V_{h}}{\theta_{h}}-\frac{V_{h h} V_{w}}{\theta_{w}}\right)\right]
\end{aligned}
$$

where $\Delta=\left[V_{h h} V_{w w}-\left(V_{h w}\right)^{2}\right] .{ }^{8}$ Equations (12) and (13) can be interpreted as follows. First, in the case where the investments are (weak) substitutes (i.e., when

\footnotetext{
${ }^{8}$ Note that all derivatives of $V$ (the two first-order derivatives $V_{h}$ and $V_{w}$, and the four secondorder derivatives $V_{h h}, V_{w w}, V_{h w}$ and $\left.V_{w h}\right)$ are evaluated at $I_{h}=I_{h}^{*}$ and $I_{w}=I_{w}^{*}$.
} 
$\left.V_{i j} \leq 0\right)$, factors affecting the spouses' equilibrium bargaining shares as of date 3 (namely, $\theta_{h}$ and $\theta_{w}$ ) will affect their investment incentives at date 2 in the same way. To be precise, any change in ex ante ownership rights $(\pi)$ that reduces (raises) an individual's share of marital surplus at date 3, will lead to lower (higher) investment incentives at date $2 .{ }^{9}$ Second, in the case where the investments are complements (i.e., when $V_{i j}>0$ ) the impact of a change in ownership rights on investment incentives will depend upon the relative importance of the investments (and we shall be more specific about this below).

\section{Prenuptial Contracts}

We now turn attention to the main issue of concern, namely, the study of the determination of the allocation $\pi$ of property rights over the marital asset (which is determined at date 1). We begin, in section 3.1., by analyzing the optimal (or efficient) asset division rule, one that maximizes the spouses' aggregate welfare and provides them with best investment incentives. We then, in section 3.2., discuss the conditions under which the spouses would agree (in equilibrium) to put the optimal asset division rule in a prenuptial contract.

3.1 Optimal Prenuptial Contracts. The optimal asset division rule is the value of $\pi$ over the interval $[0,1]$ that maximizes the joint net marital surplus

$$
S^{*}(\pi) \equiv\left(\theta_{h}+\theta_{w}\right) V\left(I_{h}^{*}, I_{w}^{*}\right)-I_{h}^{*}-I_{w}^{*},
$$

where $\theta_{h}$ and $\theta_{w}$ are defined in (5) and (6) (and depend on $\pi$ ), and $I_{h}^{*}$ and $I_{w}^{*}$ are characterized by (10) and (11) (and also depend on $\pi$ ). After differentiating $S^{*}(\pi)$ with respect to $\pi$, it follows that the optimal asset division rule, denoted $\pi^{*}$, is implicitly characterized by the first-order condition:

$$
\theta_{w}^{3}\left(\frac{V_{h}}{V_{h h}}\right)-\theta_{h}^{3}\left(\frac{V_{w}}{V_{w w}}\right)=0
$$

where the derivatives $V_{i}$ and $V_{i i}(i=h, w)$ are evaluated at the equilibrium investment levels, $I_{h}^{*}$ and $I_{w}^{*}$. Since the expression in (15) is still rather intricate, not much can be said about $\pi^{*}$ without imposing further restrictions on the function $V(\cdot)$. To proceed in a tractable manner, we derive a number of results about $\pi^{*}$ using various functional forms for the production function $V(\cdot)$. In discussing our results, we will make reference to the following properties that the production function may satisfy. Investments are said to be independent when $V_{h w}=0$. If, on the other hand, a larger investment by the male partner increases the marginal return of the investment of the female partner (and vice versa), then investments are said to be complements, i.e., $V_{h w}>0$.

\footnotetext{
${ }^{9}$ In fact, since $V$ is assumed to be strictly concave, we have that $V_{h h}<0, V_{w w}<0$ and $\Delta>0$, and since $V$ is strictly increasing $V_{h}>0$ and $V_{w}>0$. Then, $\partial \theta_{h} / \partial \pi>0$ and $\partial \theta_{w} / \partial \pi<0$ implies that the sign of $\partial I_{i}^{*} / \partial \pi$ equals the sign of $\partial \theta_{i} / \partial \pi$.
} 
3.1.2 Complementary Investments. We consider the class of functions of the CobbDouglas type, namely $V\left(I_{h}, I_{w}\right)=\left(I_{h}\right)^{\alpha_{h}}\left(I_{w}\right)^{\alpha_{w}}$ where $0<\alpha_{i}<1$ and $\alpha_{h}+\alpha_{w}<1$. These function are smooth, strictly increasing, and strictly concave. Moreover, since $V_{i j}>0$, the investments are complements. The parameters $\alpha_{h}$ and $\alpha_{w}$ capture the spouses' productivities. The ratio $\alpha_{i} / \alpha_{j}$ is a measure of productive heterogeneity between the two spouses. Our main objective is to analyze the impact of these parameters (as well as the impact of the parties' preference parameters) on the optimal allocation of marital property rights. To offer a significant benchmark for our discussion, the following proposition characterizes the optimal $\pi$ for the case where the two parties are identical in productive terms, i.e., $\alpha_{h}=\alpha_{w}$ :

Proposition 1 Assume that $V\left(I_{h}, I_{w}\right)=\left(I_{h}\right)^{\alpha}\left(I_{w}\right)^{\alpha}$ where $0<\alpha<0.5$. Then the optimal allocation of property rights over the marital asset is $\pi_{h}=\pi^{*}$ and $\pi_{w}=1-\pi^{*}$, where

$$
\pi^{*}=\frac{\mu_{w}}{\mu_{w}+\mu_{h}}
$$

This result says that the spouses' relative valuations of the asset following a divorce - i.e., the degree/extent to which each party derives utility from the asset in the regime in which couples are separated through divorce - determines the optimal shares of the asset: the spouse that has the higher "divorce valuation" should optimally have a smaller share of the asset.

The fact that the optimal marriage contract disadvantages the high valuation party is a particularly interesting result which yields the following key insight: the optimal value $\pi^{*}$ from Proposition 1 is the unique value of $\pi$ such that $\theta_{h}=\theta_{w}$, i.e., it is the unique contractual arrangement that ensures that the spouses' payoffs from divorce are equalized, that the power relations within marriage are "harmonized", and that net surplus is split equally. As a consequence, the spouses cannot make strategic use of their threat points (i.e., their divorce payoffs) in bargaining situations they encounter throughout their marriage. Both parties are thus willing to invest optimally because neither fears expropriation by the other party. Thus the optimal contract design defines a particular game between the partners, one in which the ability of individuals to engage in rent-seeking behavior is minimized. In summary, the terms of the optimal prenuptial agreement prevent the parties from behaving opportunistically ex post, thereby promoting efficient second-best investments ex ante.

Returning to the case of productive heterogeneity between the spouses, now consider the case in which $\alpha_{h} \neq \alpha_{w}$. We establish that:

Proposition 2 Assume that $V\left(I_{h}, I_{w}\right)=\left(I_{h}\right)^{\alpha_{h}}\left(I_{w}\right)^{\alpha_{w}}$ where $0<\alpha_{i}<1$ and $\alpha_{h}+\alpha_{w}<1$. Then the optimal allocation of property rights over the marital asset is $\pi_{h}=\pi^{*}$ and $\pi_{w}=1-\pi^{*}$, where

$$
\pi^{*}=\frac{\mu_{w}}{\mu_{w}+\mu_{h}}+\phi\left(\frac{\tau_{h}-\tau_{w}}{\tau_{h}+\tau_{w}}\right)
$$


where $\tau_{i} \equiv \sqrt{\frac{\alpha_{i}}{1-\alpha_{i}}}$ and $\phi \equiv \frac{\gamma_{h}+\gamma_{w}}{\mu_{h}+\mu_{w}}$.

We know that as far as the objective to balance the bargaining strengths of the parties is concerned, the first term in (17) rules out opportunistic expropriation by either party by offsetting marital bargaining powers. The second term, on the other hand, relaxes the objective to harmonize the spouses' ex ante bargaining powers by adjusting for the relative importance of the investments. In fact, if spouse $i$ 's investment is more productive compared to that of spouse $j$ (i.e., when $\alpha_{i}>\alpha_{j}$, implying, in turn, that $\tau_{i}>\tau_{j}$ ), then spouse $i$ obtains additional property rights in excess of the first term. As a consequence, the spouses equilibrium shares of the gross marital surplus will reflect the relative productivity of their respective investments, but not the parties' respective threat points (i.e., divorce payoffs). To see this, substitute the optimal value $\pi^{*}$ from Proposition 2 into (5) and (6) to obtain

$$
\theta_{i}^{*}=\frac{\tau_{i}\left(\gamma_{i}+\gamma_{j}\right)}{\tau_{i}+\tau_{j}}
$$

The intuition for this follows from the fact that when spouse $i$ 's investment is more productive than $j$ 's, then the second term of the optimal value $\pi^{*}$ translates into a greater bargaining strength of $i$ compared to $j$, which (s)he will use to obtain a larger share of the marital surplus. This will cause $i$ 's investment incentives to increase, and $j$ 's incentives to decrease, so that $I_{i}^{*}>I_{j}^{*}$. Ultimately the optimal value $\pi^{*}$ from Proposition 2 ensures - by weighting the marginal returns to investing of both spouses and balancing out marital bargaining powers - that the sum of their contributions, and thus marital surplus, is maximized.

3.1.2 Independent Investments. Consider now the case in which the investment by one party does not affect the marginal return of the other party's investment. Without loss of generality, we assume that $V\left(I_{h}, I_{w}\right)=\alpha_{h} I_{h}^{\eta}+\alpha_{w} I_{w}^{\eta}$ where $0<\eta<$ 1. The parameters $\alpha_{h}$ and $\alpha_{w}$ represent productivity parameters. The difference $\left|\alpha_{i}-\alpha_{j}\right|$ is a measure of productive heterogeneity between the two spouses. The parameter $\eta$ captures the elasticity of investments $I_{h}$ and $I_{w}$, respectively.

Proposition 3 Assume that $V\left(I_{h}, I_{w}\right)=\alpha_{h} I_{h}^{\eta}+\alpha_{w} I_{w}^{\eta}$ where $\eta \in(0,1)$. Then the optimal allocation of property rights over the marital asset is characterized as follows.

(a) If $\eta<\frac{2}{3}$, then the optimal allocation is $\pi_{h}=\pi^{*}$ and $\pi_{w}=1-\pi^{*}$, where

$$
\pi^{*}=\frac{\mu_{w}}{\mu_{w}+\mu_{h}}+\phi\left(\frac{\widehat{\tau}_{h}-\widehat{\tau}_{w}}{\widehat{\tau}_{h}+\widehat{\tau}_{w}}\right), \text { where } \widehat{\tau}_{i} \equiv \alpha_{i}^{\frac{1}{2-3 \eta}}
$$

(b) If $\eta>\frac{2}{3}$, then sole ownership [either h-ownership or w-ownership] is the optimal separation agreement.

(c) If $\eta=\frac{2}{3}$, then any $\pi \in[0,1]$ is optimal. 
The intuition for the above results are as follows. For inelastic investment, $\eta<2 / 3$, it is important that both parties invest at a medium level rather than one very high and the other very low. This is guaranteed by the allocation of property rights as captured by $\pi^{*}$ in part (a) of Proposition 3: the optimal marriage contract thus depends on the preference parameters that capture the spouses' respective valuation of the asset after divorce, and the technological parameters that capture the productivities of each parties' investment. The intuition for this finding has already been laid out in the preceding discussion of Proposition 2.

Part (b) of Proposition 3 suggests that sole ownership by one party may be desirable, at least if investments are sufficiently sensitive to surplus shares. In this case, it is no longer important to equalize the bargaining powers of the parties involved (and to adjust for the relative importance of the investments). The emphasis is rather on maximizing the investment incentive of the spouse that has the highest marginal return on investment. Consider first the case in which the parties have identical investment productivities, i.e., $\alpha_{h}=\alpha_{w}$. Then it is optimal to maximize the bargaining power of the spouse that has a higher divorce valuation, $\mu_{i}$, by making him or her the single owner of the household asset. Indeed, for sufficiently elastic investment, the marginal return on the high valuation party's investment (which, in turn, determines his or her incentives to invest in the first place) is large enough to offset the disincentive effect caused to the low valuation party by not granting her any property rights.

Consider next the case of productive heterogeneity between the spouses, i.e., $\alpha_{h} \neq \alpha_{w}$. In this setting, the optimal contractual structure is determined by the difference in divorce valuations, $\mu_{i}-\mu_{j}$, relative to the difference in investment productivities, $\alpha_{i}-\alpha_{j}$. If $\alpha_{i}-\alpha_{j}>0$, then sole ownership by the more productive $i$ generates the highest possible level of aggregate surplus, at least if either $\mu_{i}-\mu_{j}>0$ (i.e., the more productive party is also the high valuation party), or if $\mu_{i}$ is not significantly lower then $\mu_{j}$. This result is similar in spirit to the seminal work of Grossman and Hart (1986) and Hart and Moore (1990) on property rights in the theory of the firm: control by the more productive party is more desirable because her ex ante incentives to commit resources to the common enterprise are more important, while the disincentives caused to the less productive (but possibly more caring) party are a less severe problem. However, even if we allow for $\alpha_{i}-\alpha_{j}>0$, if $\mu_{j}$ is sufficiently higher then $\mu_{i}$, then sole ownership by the more caring $j$ would dominate sole ownership by the more productive $i$. The intuition is simple and follows from the fact that the investment incentives of the more caring, but less productive, party outweighed the incentives of the more productive spouse once the ratio $\frac{\mu_{j}-\mu_{i}}{\alpha_{i}-\alpha_{j}}$ exceeds a certain threshold. This is despite the adverse economic effects of reducing the incentives of the party whose input is relatively more important.

3.2. Equilibrium Prenuptial Contracts. The above analysis concerns the optimal asset division rule that, once in place, will maximize the joint surplus from marriage. But it is silent on the question of whether, or under what circumstances, will the spouses agree in equilibrium to write a prenuptial contract with this asset 
division rule. We now turn attention to this issue.

At the beginning of their relationship (date 1), the couple has the opportunity to negotiate a (legally enforceable) contract governing post-divorce asset entitlements. These negotiations are conducted in the shadow of a status quo or default asset division rule, which is determined by laws governing the division of assets on divorce. Let the legal (default) shares to $h$ and $w$ be denoted by $\pi_{h}^{0}=\pi^{0}\left(\pi^{0} \in[0,1]\right)$ and $\pi_{w}^{0}=1-\pi^{0}$ respectively. This initial legal position would generate a (default) payoff to each party from the relationship. Using backwards induction, it is easy to verify that the payoff to party $i$ if the status quo remains in place is given by

$$
u_{i}^{0}=\theta_{i}^{0} V\left(I_{h}^{0}, I_{w}^{0}\right)-I_{i}^{0},
$$

where $i$ 's share of the marital surplus $\theta_{i}^{0}$ is as in (5) and (6), but with $\pi$ replaced by the legal norm $\pi^{0}$. Similarly, $I_{i}^{0}$ is determined as in (8) and (9), but with $\theta_{i}$ replaced by $\theta_{i}^{0}$ (and hence depends on $\pi^{0}$ ). A basic assumption is that this status quo is inefficient (i.e., $\pi^{0} \neq \pi^{*}$ ). Will our two parties agree, in equilibrium, to write a contract that departs from this inefficient status quo?

3.2.1 Coasian Contract Negotiations. Suppose that the assumptions underlying the date 1 bargaining game are as follows. First, the game is one with complete information, i.e., all the parameters of the model are common knowledge between the players. Second, the spouses can bargain at little or no cost. Third, side payments between spouses are feasible. In other words, each party has enough funds to be able to make an up-front side payment to secure a negotiated agreement. ${ }^{10}$ Such a (frictionless) environment has often been described as a "Coasian" world.

An application of Coase's Theorem would thus imply that in the absence of frictions, the parties would negotiate to implement the optimal (efficient) asset division rule. In doing so, one party would in general need to offer the other party (or, as the case may be, demand from her) a side payment in return for agreeing to implement the optimal contract (Coase, 1960). This conclusion can be explicitly derived as the unique equilibrium of our model in which the two parties Nash bargain at date 1 over the value of $\pi \in[0,1]$ and the level of a side payment $s \in \mathbb{R}$, with the disagreement point $\left(u_{h}^{0}, u_{w}^{0}\right)$. Indeed, in the absence of frictions, one can establish that the equilibrium asset division rule is the optimal one, and that the Nash bargained side-payment is

$$
s^{*}=\frac{\left(u_{h}^{*}-u_{h}^{0}\right)-\left(u_{w}^{*}-u_{w}^{0}\right)}{2},
$$

where $u_{i}^{*}$ denotes $i$ 's payoff from the relationship when $\pi=\pi^{*}$. Thus the side payment will be instigated by the party whose incentives (or net benefit) from implementing the optimal asset division rule is relatively higher. ${ }^{11}$ The exact level of

\footnotetext{
${ }^{10} \mathrm{Or}$, alternatively, each party is able to make binding commitments about such a payment during marriage.

${ }^{11}$ Of course, the possibility of making side payments ensures that the parties will not let the
} 
the side payment depends on the amount by which his or her net benefit exceeds that of the other party. What needs to be emphasized, therefore, is that different legal rules (as captured by different values of $\pi^{0}$ ) will inevitably lead to different distributional outcomes. However, the ultimate result of Coasian contract negotiations (which is a contract on the optimal, or efficient, outcome) is completely unaffected by the initial legal position.

3.2.2 The Impossibility of Coasian Contract Negotiations. We now consider the (not uncommon) scenario in which couples cannot (or are unable to) make up-front sidepayments. ${ }^{12}$ We therefore reverse the Coasian set-up discussed above, and consider what would happen if no party can offer the other party (or demand from her) some side payment in return for agreeing to write a prenuptial contract.

We begin the study of this scenario by addressing the question of whether the spouses will agree to write a contract with the optimal asset division rule $\pi^{*}$ or will choose to stick with the legal norm $\pi^{0}$ (because one of the parties prefers to do so). In order to illustrate our main insights in a simplified manner, we analyze the special case in which $V=I_{h}^{1 / 3} I_{w}^{1 / 3}$ (i.e., the case in which the parties are identical in productive terms). As can bee seen from Proposition 1, the optimal asset division rule in this case would be $\pi^{*}=\mu_{w} /\left(\mu_{h}+\mu_{w}\right)$. The following proposition states our results, which are illustrated in Figure 1 and discussed after their statement:

Proposition 4 Define the following critical values:

$$
\hat{\pi}_{h}^{0} \equiv \frac{2 \mu_{w}+(\sqrt{5}-1)\left(\gamma_{h}+\gamma_{w}\right)}{2\left(\mu_{h}+\mu_{w}\right)} \quad \text { and } \quad \hat{\pi}_{w}^{0} \equiv \frac{2 \mu_{w}-(\sqrt{5}-1)\left(\gamma_{h}+\gamma_{w}\right)}{2\left(\mu_{h}+\mu_{w}\right)} .
$$

(a) If either $\hat{\pi}_{h}^{0}<\pi^{0} \leq 1$, or $0 \leq \pi^{0}<\hat{\pi}_{w}^{0}$ then both parties would agree to write a prenuptial contract with the optimal asset division rule $\pi^{*}$.

(b) Otherwise - i.e, if either $\pi^{*} \leq \pi^{0} \leq \hat{\pi}_{h}^{0}$, or $\pi^{*} \geq \pi^{0} \geq \hat{\pi}_{w}^{0}$ - then the inefficient status quo $\pi^{0}$ would remain in place.

Figure 1 depicts these results. ${ }^{13}$ It plots the value of the default rule $\pi^{0}$ against the ratio of divorce valuations, $\mu_{h} / \mu_{w}$, to illustrate under what type of default rules

problem of the division of the gains from marital contracting stand in the way of contracting on the optimal asset division rule (Coase, 1960). Note that the side payment will be arranged in such a way so as to "split the difference", i.e., so that each party receives a utility payoff that equals his or her disagreement payoff $u_{i}^{0}$ plus one-half of the gains from marital contracting.

${ }^{12}$ This scenario may occur for several reasons. Here we mention three. First, individuals about to marry may be unwilling to use "bribes" to secure a prenuptial bargain (even if they have the resources to do so). Second, individuals about to marry may be unable to borrow the (potentially large) amounts of money required to make compensating side-payments. Third, binding commitments about future actions that would induce the parties to come to the negotiating table are in general outside the scope of marriage contracts (see, for example, Smith 2003).

${ }^{13}$ Notice that "w-veto" means that $\pi^{0}$ stays in place in the relevant region because the wife prefers $\pi^{0}$ over $\pi^{*}$; similarly, "h-veto" means that $\pi^{0}$ stays in place in the relevant region because the husband prefers $\pi^{0}$ over $\pi^{*}$. Also note that the figure is based on using $\gamma_{i}=\mu_{i}(i=h, w)$, and that the limit of $\hat{\pi}_{h}^{0}$ as $\mu_{h} / \mu_{w} \rightarrow \infty$ equals $(\sqrt{5}-1) / 2$. 


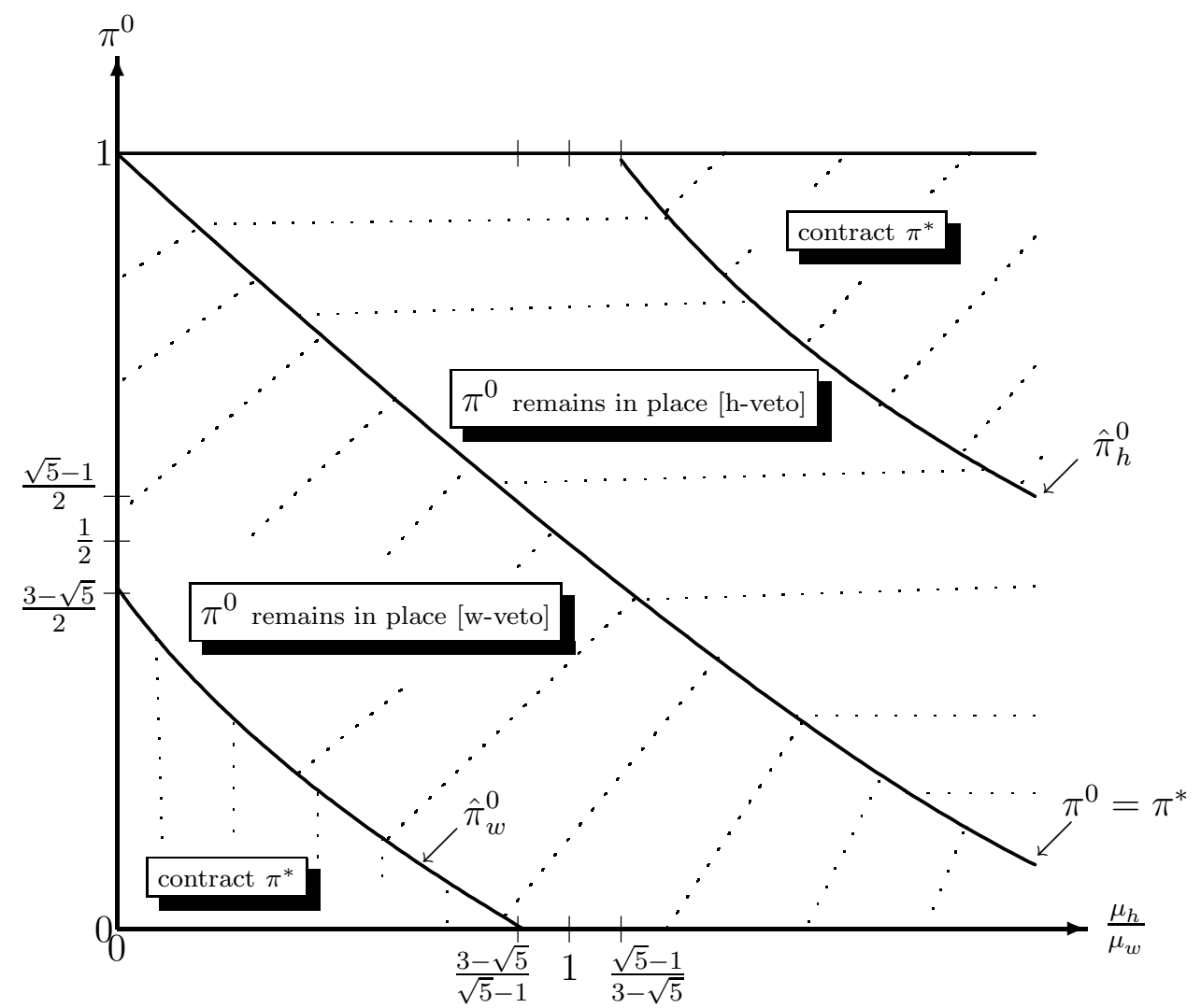

Figure 1: An Illustration of Proposition 4.

and for what type of couples prenuptial contracts will be most endemic. The two main messages are as follows:

First, notice that for any given couple, the incentive to write a marriage contract is a function of the default asset division rule $\pi^{0}$. In particular, the greater the difference between $\pi^{*}$ and $\pi^{0}$ the more likely it is that a prenuptial contract with the optimal division rule would be agreed to. The intuition behind this result is as follows. Consider an initial situation in which $\pi^{0}>\pi^{*}$, i.e., the case in which the default rule $\pi^{0}$ advantages the husband $h$ and disadvantages the wife $w$ compared to the optimal $\pi^{*}$ (opposite points hold for the symmetric case in which $\pi^{0}<\pi^{*}$ ). In these circumstances, the wife would always have an incentive to get rid of the inefficient status quo and benefit from an efficiency-enhancing change from $\pi^{0}$ to $\pi^{*}$. This is exactly because both the level of the marital surplus and the wife's $e x$ post bargaining power (and thus her share of that surplus) would increase after a change from $\pi^{0}$ to $\pi^{*}$. However, the husband knows that an agreement on $\pi^{*}$ would destroy his ex post bargaining power advantage, and thus may have an incentive to refuse to consent to a contract with $\pi^{*}$. Indeed, when the difference between $\pi^{*}$ and $\pi^{0}$ is positive but small, then $h$ has a vested interest in maintaining the inefficient division rule $\pi^{0}$ that underlies the inefficient status quo. This is precisely because the efficiency gains associated with a change from $\pi^{*}$ to $\pi^{0}$ would be too 
small to offset $h$ 's loss of bargaining power. To put it more generally, the smaller the difference between $\pi^{*}$ and $\pi^{0}$, the smaller are the efficiency gains associated with a change from $\pi^{*}$ to $\pi^{0}$ and the less likely it is that the party advantaged in the status quo would consent to such a change taking place. On the other hand, when the difference between $\pi^{*}$ and $\pi^{0}$ is sufficiently large, then the male partner would no longer refuse to consent to a contract with $\pi^{*}$ since, on net, his loss of bargaining power is more than offset by the efficiency gains that an agreement on $\pi^{*}$ would produce. A central message of the above analysis can therefore be put as follows: even with a large bargaining power advantage for one party in the status quo, which does get lost if a contract with $\pi^{*}$ is agreed, if there are enough of efficiency gains from a change to $\pi^{*}$ to redistribute during marriage, the party will agree to write a contract with the optimal asset division rule.

Second, the set of default rules under which the inefficient status quo would be replaced by the optimal $\pi^{*}$ gradually vanishes as the ratio $\mu_{h} / \mu_{w}$ approaches one. If $\mu_{h}$ and $\mu_{w}$ are sufficiently close to each other, then the inefficient status quo remains in place regardless of the value of $\pi^{0}$. Thus some degree of inequality in the parties' divorce valuations is necessary for the inefficient status quo to be replaced by the optimal asset division rule $\pi^{*}$. The intuition behind this result comes from noting that the larger the degree of inequality in the party's divorce valuations (given an arbitrary value of $\pi^{0}$ ), the larger are the efficiency gains associated with a change from $\pi^{0}$ to $\pi^{*}$, and thus the more likely it is that such a change will take place.

The above analysis concerns the choice between $\pi^{*}$ and $\pi^{0}$. We now briefly consider the situation in which the couple actually bargain over an arbitrary division rule $\pi \in[0,1]$ with the disagreement point $\left(u_{h}^{0}, u_{w}^{0}\right){ }^{14}$

We don't propose, in this paper, to explicitly characterize the result of such negotiations. Instead we report the results of a simulation that reveals a few interesting properties of the Nash bargained outcome. The results of the simulation in question are stated in Table $1 .^{15}$ The results of this simulation suggest the following sets of insights:

First, there exist critical values $\bar{\pi}_{h}^{0}$ and $\bar{\pi}_{w}^{0}\left(\bar{\pi}_{h}^{0}>\bar{\pi}_{w}^{0}\right)$ such that for values of $\pi^{0}$ over the intervals $\left[0, \bar{\pi}_{w}^{0}\right)$ and $\left(\bar{\pi}_{h}^{0}, 1\right]$ the couple would agree to write a prenuptial contract to replace the inefficient legal norm. The division rule that the couple would negotiate - we denote this agreement by $\pi^{c}$ — is systematically pegged to the legal norm $\pi^{0}$. The key insight contained here is that the equilibrium negotiated agreement does not correspond to the optimal asset division rule $\pi^{*}$ (which equals

\footnotetext{
${ }^{14}$ This means that the equilibrium negotiated asset division rule, denoted $\pi^{c}$, is the unique solution to

$$
\max _{\pi}\left[u_{h}^{N}(\pi)-u_{h}^{0}\right]\left[u_{w}^{N}(\pi)-u_{w}^{0}\right],
$$

where $u_{i}^{0}$ is $i$ 's payoff from the relationship when $\pi=\pi^{0}$ and $u_{i}(\pi)$ denotes $i$ 's payoff from the relationship for any arbitrary $\pi \in[0,1]$.

${ }^{15}$ This simulation is based on using $V=I_{h}^{1 / 3} I_{w}^{1 / 3}, \gamma_{h}=\gamma_{w}=4$ and $\mu_{h}=\mu_{w}=4$. As can be seen from Proposition 1, the optimal asset division rule in this case would be $\pi^{*}=0.5$. Notice that $u_{i}^{c}(i=h, w)$ denotes $i$ 's payoff from the relationship when $\pi=\pi^{c}$.
} 


\begin{tabular}{|c||c|c|c|c|c|c|c|c|c|c|}
\hline$\pi^{0}$ & 0 & .06 & .12 & .18 & .49 & .51 & .82 & .88 & .94 & 1 \\
\hline \hline$\pi^{c}$ & .228 & .205 & .183 & w-veto & w-veto & h-veto & h-veto & .817 & .795 & .772 \\
\hline$u_{h}^{c}$ & 3.196 & 3.051 & 2.912 & w-veto & w-veto & h-veto & h-veto & 5.616 & 5.605 & 5.584 \\
\hline$u_{h}^{0}$ & 1.777 & 2.141 & 2.515 & 2.894 & 4.693 & 4.788 & 5.617 & 5.598 & 5.505 & 5.333 \\
\hline$u_{w}^{c}$ & 5.584 & 5.605 & 5.616 & w-veto & w-veto & h-veto & h-veto & 2.912 & 3.051 & 3.196 \\
\hline$u_{w}^{0}$ & 5.333 & 5.505 & 5.598 & 5.617 & 4.788 & 4.693 & 2.894 & 2.515 & 2.141 & 1.777 \\
\hline
\end{tabular}

Table 1: Results of a Simulation.

0.5 in the context of the parameters used for this simulation). For any $\pi^{0}>\pi^{*}$, the equilibrium negotiated agreement $\pi^{c}$ would lie in the interval $\left(\pi^{*}, \pi^{0}\right)$. Similarly, for any $\pi^{0}<\pi^{*}$, the equilibrium negotiated agreement $\pi^{c}$ would lie in the interval $\left(\pi^{0}, \pi^{*}\right)$. This makes intuitive sense: the legal norm used in a society confers bargaining power in contract negotiations via its impact on the disagreement point.

Second, for values of $\pi^{0}$ over the interval $\left[\bar{\pi}_{w}^{0}, \bar{\pi}_{h}^{0}\right]$ the couple would fail to reach an agreement. This is exactly because the efficiency gains associated with the contract that the couple would negotiate are small, and the party with a bargaining power advantage in the status quo has a vested interest in maintaining the inefficient legal norm $\pi^{0}$.

Although the above analysis does not offer an analytical characterization of the equilibrium when the two partners actually bargain over the asset division rule, it is conceivable that the insights we obtain are robust to a general and complete characterization of these negotiations.

Are there pointers for policy? When up-front side payments are beyond the scope of marital contracting, we have shown above that there is a close and deep connection between legal norms regulating the division of marital assets upon divorce and a couple's incentives to write prenuptial contracts. The immediate, main policy consequences are thus self-evident: although privately negotiated marital contracts can provide incentives for greater relationship-specific investment, individuals about to marry may be unwilling to discuss the possibility of making an efficiency-enhancing private contract for fear that the contract may imperil the existing status quo. In such circumstances, legal norms governing divorce continue to directly influence the economic incentives of married couples. It would therefore seem desirable that policy-makers should understand the efficiency consequences of their decisions and should therefore take these consequences into account when making their decisions.

\section{An Application: Property LaW for Divorcing Couples}

The application that inspired this analysis is the ongoing debate among policy makers as to the appropriate role and extent of marital property laws. There are several polar legal structures currently considered by policy makers for handling the problem of property divorce settlements. The three most commonly discussed 
are: (1) the 'equal division of property model'; (2) the 'needs model'; and (3) the 'compensation model'.

Each of these three assignments of property rights creates its own set of bargaining endowments. Because different legal rules give various amounts of "bargaining chips" (in the language coined by Mnookin and Kornhauser, 1979) to spouses, changing the standard would affect each party's bargaining strength and would therefore influence decisions and outcomes within marriage. In this section, we provide a comparative evaluation of the efficiency properties of the aforementioned legal structures.

We develop our ideas in this section in a slightly different framework - one in which the question faced by courts is how to weight domestic endeavour (i.e., home production) against the grind of wage-earning in divorce settlements. We explicitly think of the investments $I_{h}$ and $I_{w}$ as contributions made by each spouse towards the acquisition of the family asset by performing domestic duties, thereby releasing one's partner for gainful employment. Intuitively, when one spouse specializes at home, the cost of such an investment is the foregone opportunity for achievement in the outside labor market. Hence, let $u_{h}=w_{h}\left(1-I_{h}\right)+\gamma_{h} V\left(I_{h}, I_{w}\right)-T$ and $u_{w}=w_{w}\left(1-I_{w}\right)+\gamma_{w} V\left(I_{h}, I_{w}\right)+T$, where each party allocates one unit of time between domestic production and the pursuit of a career in the labor market. This formalization captures the idea that an investment $I_{i}$ has a public good component (i.e., home production) as well as a private good component (i.e., a successful career). Note that we may think of the magnitude of investment $I_{i}$ as $i$ 's degree of specialization in the household sphere. The parameters $w_{h}$ and $w_{w}$ capture the exogenously given labor market wage rates of $h$ and $w$. If the couple divorce each other at date 3 , then their divorce payoffs are $d_{h}=w_{h}\left(1-I_{h}\right)+\mu_{h} \pi V\left(I_{h}, I_{w}\right)$ and $d_{w}=w_{w}\left(1-I_{w}\right)+\mu_{w}(1-\pi) V\left(I_{h}, I_{w}\right)$. Along the lines of our baseline model, it is easy to check that a marital surplus does exist. The Nash bargained payoffs to the spouses at date 3 are therefore $u_{h}^{N}=w_{h}\left(1-I_{h}\right)+\theta_{h} V\left(I_{h}, I_{w}\right)$ and $u_{w}^{N}=$ $w_{w}\left(1-I_{w}\right)+\theta_{w} V\left(I_{h}, I_{w}\right)$, where $\theta_{h}$ and $\theta_{w}$ are defined in (5) and (6). It is now easy to verify that the investments, $\left(I_{h}, I_{w}\right)$, chosen at date 2 will satisfy the following pair of first-order conditions:

$$
\theta_{h} V_{h}\left(I_{h}^{*}, I_{w}^{*}\right)=w_{h} \quad \text { and } \quad \theta_{w} V_{w}\left(I_{h}^{*}, I_{w}^{*}\right)=w_{w},
$$

where the market wage rate $w_{i}$ represents the opportunity cost of sinking a marriagespecific investment. Focusing on essentials we restrict attention to the following parametric functional form for the value of the household asset: $V=2 \sqrt{I_{h}}+$ $2 \sqrt{I_{w}}$. To capture the fact that the spouses may face different opportunities in the outside labor market, we assume that $w_{h} \geq w_{w}$. In addition, it is assumed that the degree/extend to which party $i$ derives utility from the asset in the regime in which couples are separated through divorce differs between spouses. Specifically, we assume that the less affluent female partner ( since $w_{w} \leq w_{h}$ ) has higher divorce valuation for the asset than the more affluent male partner, i.e., $\mu_{w} \geq \mu_{h}$. 
"Equal division approach". This in effect calls for equal sharing. ${ }^{16}$ The underlying premise of this approach is that marriage is a joint enterprise in which the partners pool their efforts and resources towards a shared well-being, and thus equal sharing of the couple's assets is fair and appropriate. One advantage of equal sharing is that it is easily understood, and thus gives clear guidelines as to likely outcomes in the event of divorce. In our framework, it is natural to assume that a property law based upon the principles of the equal division of property approach is captured by $\pi^{S}=\frac{1}{2}$. We denote the investments chosen under $\pi^{S}$ by $\left(I_{h}^{S}, I_{w}^{S}\right)$. Since we are considering here a model where the value of the asset $V$ takes on an explicit functional form we obtain a very simple solution for the optimal choice of investments for the two parties:

$$
I_{i}^{S}=\left[\frac{2\left(\gamma_{h}+\gamma_{w}\right)+\mu_{i}-\mu_{j}}{4 w_{i}}\right]^{2} .
$$

"Compensation approach". The basic idea here is that any assets arising from a marriage should be allocated to the parties according to their human contributions to the partnership. The general principle underlying this approach is that fair account should be taken of any economic advantage derived by either spouse from the human contributions by the other. This covers, for example, the spouse who stays at home working in the household (or only works part-time), a wife who supports her husband through college, or a spouse who refuses promotion so as not to disrupt family life. In our framework, since $I_{h}$ and $I_{w}$ are not verifiable to outside parties, but $d I_{h} / d w_{h}<0$ and $d I_{w} / d w_{w}<0$, it is appealing to assume that a property law based upon the principles of the 'compensation approach' is captured by

$$
\pi^{C}=\frac{w_{w}}{w_{h}+w_{w}} .
$$

In line with the idea of compensation, this ensures that the low-wage party (i.e., the one who will ultimately sink a relatively high marriage-specific investment) obtains a relatively larger fraction of the asset in the event of a divorce than the high-wage party. ${ }^{17}$ The equilibrium investments of $h$ and $w$ under $\pi^{C}$ are:

$$
I_{i}^{C}=\left[\frac{\left(\gamma_{h}+\gamma_{w}\right)\left(w_{h}+w_{w}\right)+\mu_{i} w_{j}-\mu_{j} w_{i}}{2 w_{i}\left(w_{h}+w_{w}\right)}\right]^{2} .
$$

It is easy to see that the investment incentive of the female partner will be higher and that of the male partner will be lower under $\pi^{C}$ compared to $\pi^{S}$, that is,

\footnotetext{
${ }^{16}$ For example, in Scotland as well as in many civil law countries and several American states, a property regime with a statutory presumption in favor of equal division upon divorce (unless there are special circumstances) applies to the spouses (see, e.g., Tee 2001 and Smith 2003).

${ }^{17}$ It may be noted that implementation of the compensation approach (at least in the way that we describe it) would involve information revelation problems in a heterogeneous population (unless the $w_{i}$ 's are the means for genders).
} 
$I_{w}^{C}>I_{w}^{S}$ and $I_{h}^{C}<I_{h}^{S}$. The intuition for this is simple and follows from the fact that $\pi^{C}$ translates into a bargaining advantage of the low-wage party (i.e., the wife), which she will use to obtain more than an equal split of marriage surplus. A direct implication of this is that $w$ will invest more under $\pi^{C}$ compared to $\pi^{S}$. On the other hand, the low valuation party $h$, anticipating that $w$ will "hold him up" at the bargaining stage, will invest less under $\pi^{C}$ compared to $\pi^{S}$.

'Needs approach'. In England and Wales, until very recently, the predominant discourse as to the appropriate role of property law was firmly needs based. Most practitioners agreed that the purpose of the law in this area should be to provide for reasonable future requirements of the former spouses. Following Tee (2001) who argues that in a majority of cases, the requirements of the more needy (e.g., less affluent) wife absorb most of the marital assets, it is natural to assume that one property law based upon the principles of the 'needs approach' makes the less affluent party (here the wife, because $w_{w}<w_{h}$ ) the single owner of the asset. Therefore we set $\pi^{N}=0$. The equilibrium investments under $\pi^{N}$ are:

$$
I_{h}^{N}=\left[\frac{\left(\gamma_{h}+\gamma_{w}\right)-\mu_{w}}{2 w_{h}}\right]^{2} \text { and } I_{w}^{N}=\left[\frac{\left(\gamma_{h}+\gamma_{w}\right)+\mu_{w}}{2 w_{h}}\right]^{2} .
$$

The investment incentive of the female partner will be higher under $\pi^{N}$ compared to $\pi^{C}$, and therefore higher than under $\pi^{S}$. The investment incentive of the male partner will be lower under $\pi^{N}$ compared to $\pi^{C}$, and therefore lower than under $\pi^{S}$.

Comparing equilibrium investment levels under the different legal structures, we obtain the following ranking of divorce asset division regimes:

Proposition 5 Assume that $V\left(I_{h}, I_{w}\right)=2 \sqrt{I_{h}}+2 \sqrt{I_{w}}$ and let $\Lambda \equiv w_{h} / w_{w}$. Then there exist critical values denoted $\Lambda^{\prime}$ and $\Lambda^{\prime \prime}$, where

$$
\Lambda^{\prime} \equiv \frac{4\left(\gamma_{h}+\gamma_{w}\right)+\mu_{w}-3 \mu_{h}}{4\left(\gamma_{h}+\gamma_{w}\right)-3 \mu_{w}+\mu_{h}} \quad \text { and } \quad \Lambda^{\prime \prime} \equiv \frac{2\left(\gamma_{h}+\gamma_{w}\right)+\mu_{w}-\mu_{h}}{2\left(\gamma_{h}+\gamma_{w}-\mu_{w}\right)}
$$

such that:

(a) if $\Lambda>\Lambda^{\prime \prime}$, then the 'needs' approach is the best assignment of property rights, followed by the 'compensation' approach, which in turn dominates 'equal sharing'; (b) if $\Lambda<\Lambda^{\prime}$, then 'equal sharing' is the best assignment of property rights; it dominates the 'compensation' approach, which in turn dominates the 'needs' approach.

(c) Otherwise, if $\Lambda^{\prime} \leq \Lambda \leq \Lambda^{\prime}$, then 'equal sharing' and the 'needs' model are dominated by the 'compensation' approach.

Proof. See the Appendix.

Figure 2 illustrates the main insights of Proposition 5. It plots the ratio of extrahousehold opportunities, $w_{h} / w_{w}$, against the ratio of divorce valuations, $\mu_{h} / \mu_{w}$, to highlight the regions in which the different default asset division regimes will be 


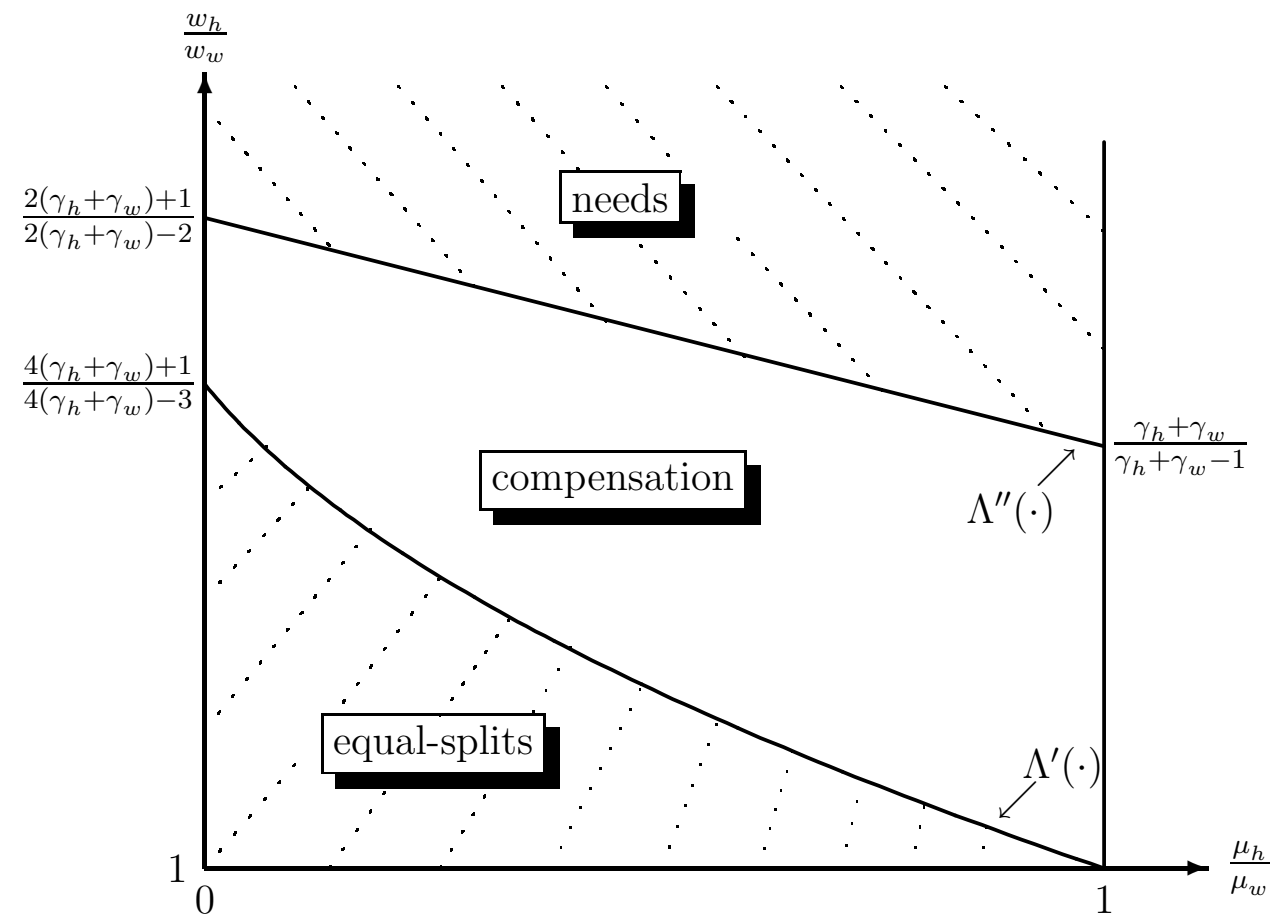

Figure 2: An Illustration of Proposition 5.

optimal. What is clear from the figure is that the relative merit of the various legal regimes depends on whether we consider societies in which the opportunities of women outside the household differ consistently from those of men (i.e., the "gender earnings gap", $w_{h}-w_{w}$, is large); or whether it is the case that women have opportunities outside the household that are roughly the same as those of men (i.e., the gap $w_{h}-w_{w}$ is sufficiently narrow). It is worth highlighting the welfare implications of the different divorce asset division regimes.

We first restrict our attention to the case where there are consistent and substantial male wage advantages, i.e., $w_{h} \gg w_{w}$. It may appear unequal, but to the extend that the husband has higher returns outside marriage, our two parties are assigned to different roles within the relationship. The wife has a large marriagespecific investment to sink that directly benefits her partner since, on the margin, her opportunity cost is comparatively low. The husband, on the other hand, has a comparative advantage in accumulating resources (primarily earning power) that are valuable outside marriage. Proposition 5(a) suggests that the 'needs' model in this case delivers the second-best. The intuition is that allocating sole ownership to the female partner provides incentives for her to specialize in the household-sphere at the optimal scale so that the net marital surplus under the 'needs' model is maximized. Any move to a sub-optimal legal structure (to either the 'compensation' or 'equal division' model) would create the behavioral risk of male opportunism, i.e., the husband could now expropriate part of the wife's specific investment by threatening divorce. This would induce the female partner to start to behave defensively by spending more than the optimal amount of time at work and less time on their home (by (18) to (20)). The 'needs' approach is thus relevant in relation to 
women's incentives to sink a heavy marriage-specific investment without facing the behavioral risk of male opportunism in bargaining situations the couple encounter throughout the partnership.

However, the case of substantial male wage advantages might be considered an unrealistic description of some societies, and one can detect an optimal response in the legal environment when both spouses start having sufficiently similar opportunities in the outside labor market (i.e, when $w_{h} \approx w_{w}$ ). In this case, the structural positions men and women occupy within and outside marriage are much the same: both can accumulate resources (earning power) that are valuable outside marriage at a comparable scale. When their roles outside marriage are similar, it is desirable to have the parties share the responsibility of undertaking marriage-specific investments. Hence it is optimal to endow both parties with balanced incentives to sink marriage-specific investments. It is not surprising, then, that the 'equal-splits' or, as the case may be, the 'compensation' model produces the second best marital surplus (Propositions 5(b) and 5(c)). In contrast, a regime that awards sole ownership of the asset to the female partner is the worst assignment of property rights. It may generate a moral hazard problem insofar as it fails to provide the wife with sufficient incentives to invest efficiently in accumulating market-compatible skills: the female partner does too much of the unpaid household work (i.e., chooses too large a degree of specialization in the household sphere) and spends too little time at market work despite her facing the same opportunities in the outside labor market as the male partner. In sum, the increasing opportunities of married women outside the household, which can be seen as an indication of women's increasing bargaining power within it, should be accompanied by the demise of female presumption in property disputes and by legal changes towards "equal splits" in divorce settlements.

\section{Summary and Concluding Remarks}

Although the distributive problems of divorce may be most visible at its occurrence, it is increasingly understood that divorce law can also influence a broad range of decisions in intact families - e.g., whether and when to marry, the number, timing, and upbringing of children, the allocation of resources during marriage, and whether and when to divorce. ${ }^{18}$ Indeed, many practitioners and policy makers often proclaim that the liberalization of divorce laws over the last thirty years has undermined the role of marriage as an institution for providing couples with the confidence to make long-term investments in their relationship. Yet the incentive effects associated with alternative legal regimes are poorly understood in practice, and no clear theoretical framework has emerged for the study of these problems. Our main concern in this paper has been to understand why the "success" of marriage can depend, in part, on the legal context in which couples decide to marry and to stay married.

\footnotetext{
${ }^{18}$ See, e.g., Mnookin and Kornhauser (1979), Peters (1986), Cohen (1987), Gray (1998), Clark (1999), and Chiappori et al. (2002).
} 
Our theoretical model shows that the terms of divorce have not only distributive consequences ex post but can also have efficiency consequences in intact households, by influencing spousal incentives to make investments in relationship-specific assets. To the extent that specific investments determine the average quality of marriage, this creates a role for the use of ex ante separation agreements that stipulate the allocation of marital assets upon divorce. We derive several results concerning the optimal and the equilibrium ex ante separation agreement. A fundamental principle that governs the optimal marriage contract is to equalize the parties' economic positions after divorce (thereby "balancing out" spousal bargaining powers within marriage) and to weight their investment incentives. Hence, by giving backing to the marital bargaining process, the terms of pre-nuptial agreements prevent parties behaving opportunistically ex post, thereby promoting efficient investment ex ante.

Several extensions and generalizations suggest themselves, some of which are the subject of a sequel to the present paper.

- A simplifying but somewhat restrictive assumption that underlies the model is that divorce is ruled out in equilibrium. Although many of the main qualitative insights would be robust to allowing divorce to occur with positive probability, it would be useful to formally address this issue partly because if the likelihood of divorce is real then the incentives of the spouses would be altered from our current analysis. One potential way of modelling this issue would be to impose a positive shock to the parties' divorce payoffs (Weiss and Willis, 1985; Clark, 1999). By incorporating such payoff uncertainty, the equilibrium divorce rate can be determined, which, in turn, will influence and be influenced by specific marital investments and the terms of divorce.

- A further step towards realism would be to embed the present framework within a model of marriage markets thus endogeneizing the decision to marry. It seems conceivable that the possibility of writing prenuptial contracts alters the value of potential marriages between different people. It would be of great interest, therefore, to determine how the act of writing "prenuptials" affects the choice of spouse (Allen, 1992).

- In deriving our results we assumed that contracts contingent on marriagespecific investments are not verifiable by third parties. A possible way to contract on investment levels without relying on verifiability would be the posting of "marital bonds" (Lommerud, 1989). For example, if a wife sinks a heavy marriage-specific investment, the husband makes a monetary transfer to her. If the marriage is success than the money is jointly used by the spouses; otherwise, if the couple divorce each other, the wife keeps the money. It would be of interest to explore whether such bonds can to some degree substitute for prenuptial contracts in inducing optimal marital investments. ${ }^{19}$

\footnotetext{
${ }^{19} \mathrm{~A}$ prenuptial contract could of course not only be about the division of marrital assets, but it could also prescribe a fine for the leaving party. However, a lump-sum fine for the leaving party would not affect marginal returns to investing, and hence would have no effect on equilibrium investment incentives.
} 
- We use the Nash bargaining solution to characterize the outcome of marital negotiations. Alternatively, one could consider the "outside option bargaining" protocol. Under this, if one party's outside option is binding, then she receives her divorce payoff while the other party receives the remaining surplus. In the light of the work of Chiu (1998) and De Meza and Lockwood (1998), it would be interesting to study how such an alternative bargaining solution would affect our results.

- Finally, while the present model explicitly addresses the effect of holdup on marital investment, the relational contracting literature (Halonen, 2002; Baker et al., 2002) suggests some qualifications to our argument. The extent of holdup, for example, will be reduced insofar as the spouses are able to punish opportunistic behavior through the threat of non-legal sanctions. Rainer (2003) extends the present model to allow for repeated marital investments, demonstrating that explicit prenuptial contracts might still be used to discipline the spouses incentives to renege on implicit relational agreements.

There are, of course, a wide range of interesting extensions to our analysis. Despite the questions opened up by moving to a richer framework, we believe that a model of marriage that recognizes the presence of certain transaction costs inside the family has to be an integral part of a unified theory of marriage and divorce.

\section{APPENDIX}

Proof of Propositions 1 and 2. Step 1 (General Characterization): The firstorder condition characterizing the optimal $\pi^{*}$ is

$$
\frac{\partial S^{*}(\pi)}{\partial \pi}=\left[\frac{\partial \theta_{h}}{\partial \pi}+\frac{\partial \theta_{w}}{\partial \pi}\right] V+\left(\theta_{w}+\theta_{h}\right)\left[V_{h} \frac{\partial I_{h}^{*}}{\partial \pi}+V_{w} \frac{\partial I_{w}^{*}}{\partial \pi}\right]-\frac{\partial I_{h}^{*}}{\partial \pi}-\frac{\partial I_{w}^{*}}{\partial \pi} .
$$

Since by (5) and (6)

$$
\frac{\partial \theta_{h}}{\partial \pi}+\frac{\partial \theta_{w}}{\partial \pi}=0
$$

it follows using (10) and (11) that

$$
\frac{\partial S^{*}(\pi)}{\partial \pi}=\theta_{w} V_{h} \frac{\partial I_{h}^{*}}{\partial \pi}+\theta_{h} V_{w} \frac{\partial I_{w}^{*}}{\partial \pi} .
$$

After substituting for the derivatives of the equilibrium investment levels [using (12) and (13)], simplifying, rearranging and finally using the first-order conditions in (10) and (11) to substitute for $V_{h}$ and $V_{w}$ we obtain

$$
\frac{\partial S^{*}(\pi)}{\partial \pi}=\theta_{h}^{3}\left(-\frac{V_{w}}{V_{w w}}\right)-\theta_{w}^{3}\left(-\frac{V_{h}}{V_{h h}}\right) .
$$

Step 2. Suppose that $V\left(I_{h}, I_{w}\right)=\left(I_{h}\right)^{\alpha_{h}}\left(I_{w}\right)^{\alpha_{w}}$ where $0<\alpha_{i}<1$ and $\alpha_{h}+\alpha_{w}<1$. It follows from an application of (A.4) - after substituting for the equilibrium values of $V_{h}, V_{w}, V_{h h}$ and $V_{w w}$ - that

$$
\frac{\partial S^{*}(\pi)}{\partial \pi}=\frac{\theta_{h}^{3} I_{w}^{*}}{1-\alpha_{w}}-\frac{\theta_{w}^{3} I_{h}^{*}}{1-\alpha_{h}} .
$$


After simultaneously solving the first-order conditions in (10) and (11), one obtains the equilibrium investments

$$
I_{h}^{*}=\left[\left(\alpha_{h} \theta_{h}\right)^{1-\alpha_{w}}\left(\alpha_{w} \theta_{w}\right)^{\alpha_{w}}\right]^{\frac{1}{1-\alpha_{h}-\alpha_{w}}} \quad \text { and } \quad I_{w}^{*}=\left[\left(\alpha_{h} \theta_{h}\right)^{\alpha_{h}}\left(\alpha_{w} \theta_{w}\right)^{1-\alpha_{h}}\right]^{\frac{1}{1-\alpha_{h}-\alpha_{w}}} \text {. }
$$

After combining (A.5) and (A.6), simplifying and rearranging, it follows that

$$
\frac{\partial S^{*}(\pi)}{\partial \pi}=\frac{\alpha_{w} \theta_{h}^{2}}{1-\alpha_{w}}-\frac{\alpha_{h} \theta_{w}^{2}}{1-\alpha_{h}}
$$

We then obtain [using (A.7), (5) and (6)] that

$$
\frac{\partial S^{*}(\pi)}{\partial \pi} \gtreqless 0 \Longleftrightarrow-\left(\tau_{h}+\tau_{w}\right)\left[\pi\left(\mu_{h}+\mu_{w}\right)-\mu_{w}\right]+\left(\tau_{h}-\tau_{w}\right)\left[\gamma_{h}+\gamma_{w}\right] \gtreqless 0 .
$$

where $\tau_{i} \equiv \sqrt{\alpha_{i} /\left(1-\alpha_{i}\right)}(i=h, w)$. Hence, it follows that $S^{*}$ has a stationary point at $\pi=\pi^{*}$ [which is stated in Proposition 2], and [after differentiating (A.7) w.r.t to $\pi$ ] that

$$
\frac{\partial^{2} S^{*}\left(\pi^{*}\right)}{\partial \pi^{2}}<0
$$

Hence we have established that the stationary point $\pi=\pi^{*}$ is the point at which $S^{*}$ achieves its maximum over the interval $[0,1]$. Proposition 1 follows along the line of this proof, taking the limiting case $\alpha_{h} \rightarrow \alpha_{w}$. QED

Proof of Proposition 3. Suppose that $V=\alpha_{h} I_{h}^{\eta}+\alpha_{w} I_{w}^{\eta}$, where $\eta \in(0,1)$. From the first-order conditions in (10) and (11) one obtains the equilibrium investments

$$
I_{h}^{*}=\left(\eta \alpha_{h} \theta_{h}\right)^{\frac{1}{1-\eta}} \text { and } I_{w}^{*}=\left(\eta \alpha_{w} \theta_{w}\right)^{\frac{1}{1-\eta}} .
$$

It follows from an application of (A.3) - after substituting for the equilibrium values of $V_{h}, V_{w}$ and the derivatives of $I_{h}^{*}$ and $I_{w}^{*}$ - that

$$
\frac{\partial S^{*}(\pi)}{\partial \pi}=\left[\alpha_{h}^{\eta} \theta_{h}^{3 \eta-2}\right]^{\frac{1}{1-\eta}}-\left[\alpha_{w}^{\eta} \theta_{w}^{3 \eta-2}\right]^{\frac{1}{1-\eta}} .
$$

We then obtain [using (A.10), (5) and (6)] that

$$
\frac{\partial S^{*}(\pi)}{\partial \pi} \gtreqless 0 \Longleftrightarrow-\left(\widehat{\tau}_{h}+\widehat{\tau}_{w}\right)\left[\pi\left(\mu_{h}+\mu_{w}\right)-\mu_{w}\right]+\left(\widehat{\tau}_{h}-\widehat{\tau}_{w}\right)\left[\gamma_{h}+\gamma_{w}\right] \gtreqless 0 .
$$

where $\widehat{\tau}_{i}=\alpha_{i}^{\frac{1}{2-3 \eta}}(i=h, w)$. Hence, it follows that $S^{*}$ has a stationary point at $\pi=\pi^{*}$ [which is stated in Proposition 3(a)], and [after differentiating (A.10) w.r.t to $\pi$ ] that

$$
\frac{\partial^{2} S^{*}\left(\pi^{*}\right)}{\partial \pi^{2}} \lesseqgtr 0 \Longleftrightarrow \eta \lesseqgtr \frac{2}{3} .
$$

Hence we have established that if $\eta<\frac{2}{3}$ (if $\eta>\frac{2}{3}$ ), then the stationary point $\pi=\pi^{*}$ is the point at which $S^{*}$ achieves a maximum (minimum) over the interval $[0,1]$. QED 
Proof of Proposition 4. The proposition concerns the players' choices between the optimal $\pi^{*}$ and an arbitrary $\pi^{0} \in[0,1]$. Suppose that $V=I_{h}^{1 / 3} I_{w}^{1 / 3}$. The optimal division rule in this case is $\pi^{*}=\mu_{w} /\left(\mu_{h}+\mu_{w}\right)$. Player $i$ 's $(i=h, w)$ equilibrium payoff from the relationship when $\pi^{*}=\mu_{w} /\left(\mu_{h}+\mu_{w}\right)$ would be: ${ }^{20}$

$$
u_{h}\left(\pi^{*}\right)=2\left[\left(\frac{\theta_{i}^{*}}{3}\right)^{2}\left(\frac{\theta_{j}^{*}}{3}\right)\right]=\frac{2}{27}\left[\left(\frac{\gamma_{h}+\gamma_{w}}{2}\right)^{3}\right] .
$$

Player $i$ 's $(i=h, w)$ equilibrium payoff from the relationship when $\pi=\pi^{0}$ would be:

$$
u_{i}\left(\pi^{0}\right)=2\left[\left(\frac{\theta_{i}^{0}}{3}\right)^{2}\left(\frac{\theta_{j}^{0}}{3}\right)\right] \quad(i \neq j),
$$

where $\theta_{i}^{0}(i=h, w)$ is as in (5) and (6), but with $\pi$ replaced by $\pi^{0}$. Now define $\varphi_{h}\left(\pi^{0}\right) \equiv u_{h}\left(\pi^{*}\right)-u_{h}\left(\pi^{0}\right)$ and $\varphi_{w}\left(\pi^{0}\right) \equiv u_{w}\left(\pi^{*}\right)-u_{w}\left(\pi^{0}\right)$. After setting $\varphi_{h}\left(\pi^{0}\right)=$ $\varphi_{w}\left(\pi^{0}\right)=0$ and some simplification, it follows that

$$
\varphi_{h}\left(\pi^{0}\right)=0 \Longleftrightarrow\left(\pi^{*}-\pi^{0}\right)\left[-\bar{\mu}^{2}\left(\pi^{0}\right)^{2}+\bar{\mu}\left(2 \mu_{w}-\bar{\gamma}\right) \pi^{0}+\bar{\gamma}\left(\mu_{w}+\bar{\gamma}\right)-\mu_{w}^{2}\right]=0
$$

and

$$
\varphi_{w}\left(\pi^{0}\right)=0 \Longleftrightarrow\left(\pi^{*}-\pi^{0}\right)\left[\bar{\mu}^{2}\left(\pi^{0}\right)^{2}-\bar{\mu}\left(2 \mu_{w}+\bar{\gamma}\right) \pi^{0}+\bar{\gamma}\left(\mu_{w}-\bar{\gamma}\right)+\mu_{w}^{2}\right]=0,
$$

where $\bar{\gamma}=\gamma_{h}+\gamma_{w}, \bar{\mu}=\mu_{h}+\mu_{w}$ and $\pi^{*}=\mu_{w} /\left(\mu_{h}+\mu_{w}\right)$. It is now easy to show that $\pi^{*}$ and $\hat{\pi}_{h}^{0}$ [which is stated in the proposition] are the two unique values of $\pi^{0}$ over the interval $[0,1]$ such that $\varphi_{h}\left(\pi^{0}\right)=0$. Similarly, it is readily checked that $\pi^{*}$ and $\hat{\pi}_{w}^{0}$ [which is stated in the proposition] are the two unique values of $\pi^{0}$ over the interval $[0,1]$ such that $\varphi_{w}\left(\pi^{0}\right)=0$. We then note that

$$
\frac{\partial \varphi_{h}\left(\pi^{*}\right)}{\partial \pi^{0}}<0 \quad \text { and } \quad \frac{\partial \varphi_{h}\left(\hat{\pi}_{h}^{0}\right)}{\partial \pi^{0}}>0 .
$$

This implies that for any $\pi^{0} \in\left[0, \pi^{*}\right) \cup\left(\hat{\pi}_{h}^{0}, 0\right]$, player $h$ would prefer $\pi^{*}$ over $\pi^{0}$, while for any $\pi^{0} \in\left[\pi^{*}, \hat{\pi}_{h}^{0}\right]$ player $h$ would prefer $\pi^{0}$ over $\pi^{*}$. We also note that

$$
\frac{\partial \varphi_{w}\left(\hat{\pi}_{w}^{0}\right)}{\partial \pi^{0}}<0 \text { and } \quad \frac{\partial \varphi_{w}\left(\pi^{*}\right)}{\partial \pi^{0}}>0 .
$$

This implies that for any $\pi^{0} \in\left[0, \hat{\pi}_{w}^{0}\right) \cup\left(\pi^{*}, 1\right]$ player $w$ would prefer $\pi^{*}$ over $\pi^{0}$, while for any $\pi^{0} \in\left[\hat{\pi}_{w}^{0}, \pi^{*}\right]$ player $w$ would prefer $\pi^{0}$ over $\pi^{*}$. The proposition now follows immediately since $\pi^{*}$ is jointly preferred by $h$ and $w$ for any $\pi^{0} \in$ $\left[0, \hat{\pi}_{w}^{0}\right) \cup\left(\hat{\pi}_{h}^{0}, 1\right] . \mathrm{QED}$

\footnotetext{
${ }^{20}$ Recall that $\pi^{*}=\mu_{h} /\left(\mu_{h}+\mu_{w}\right)$ is the unique value of $\pi$ such that $\theta_{h}=\theta_{w}$.
} 
Proof of Proposition 5. Suppose that $V=2 \sqrt{I_{h}}+2 \sqrt{I_{w}}$, let $\Lambda \equiv w_{h} / w_{w}$, and restrict attention to parameters satisfying $w_{h} \geq w_{w}$ and $\mu_{w} \geq \mu_{h}$. Then the joint net marital surplus for an arbitrary $\pi^{k} \in\left\{\pi^{N}, \pi^{C}, \pi^{S}\right\}$ would be:

$$
S\left(\pi^{k}\right)=w_{h}\left[1-\left(\frac{\theta_{h}^{k}}{w_{h}}\right)^{2}\right]+w_{w}\left[1-\left(\frac{\theta_{h}^{k}}{w_{h}}\right)^{2}\right]+2\left(\gamma_{h}+\gamma_{w}\right)\left[\frac{\theta_{h}^{k}}{w_{h}}+\frac{\theta_{w}^{k}}{w_{w}}\right],
$$

where $\theta_{i}^{k}(i=h, w)$ is as in (5) and (6), but with $\pi$ replaced by $\pi^{k} \in\left\{\pi^{N}, \pi^{C}, \pi^{S}\right\}$. After subtracting $S\left(\pi^{C}\right)$ from $S\left(\pi^{N}\right)$, simplifying and re-arranging, it follows that

$$
S\left(\pi^{N}\right)-S\left(\pi^{C}\right) \gtreqless 0 \Longleftrightarrow \Lambda \gtreqless \frac{2\left(\gamma_{h}+\gamma_{w}\right)-\left(\theta_{h}^{N}+\theta_{h}^{C}\right)}{2\left(\gamma_{h}+\gamma_{w}\right)-\left(\theta_{w}^{N}+\theta_{w}^{C}\right)}
$$

After substituting $\pi^{N}=0$ and $\pi^{C}=1 /(1+\Lambda)$ into (5) and (6) to obtain $\theta_{h}^{N}$ and $\theta_{h}^{C}$ respectively, re-arranging and simplifying, it follows that

$$
S\left(\pi^{N}\right)-S\left(\pi^{C}\right) \gtreqless 0 \Longleftrightarrow 2\left(\gamma_{h}+\gamma_{w}\right)(\Lambda-1)+\mu_{h} \gtreqless \mu_{w}(2 \Lambda+1)
$$

Hence, it follows that there exists a critical value $\Lambda^{\prime \prime}$ [which is stated in Proposition 4] such that $S\left(\pi^{N}\right)-S\left(\pi^{C}\right) \gtreqless 0 \Longleftrightarrow \Lambda \gtreqless \Lambda^{\prime \prime}$.

After subtracting $S\left(\pi^{C}\right)$ from $S\left(\pi^{S}\right)$, simplifying and re-arranging, it follows that

$$
S\left(\pi^{S}\right)-S\left(\pi^{C}\right) \gtreqless 0 \Longleftrightarrow \Lambda \gtreqless \frac{2\left(\gamma_{h}+\gamma_{w}\right)-\left(\theta_{h}^{S}+\theta_{h}^{C}\right)}{2\left(\gamma_{h}+\gamma_{w}\right)-\left(\theta_{w}^{S}+\theta_{w}^{C}\right)}
$$

After substituting $\pi^{S}=\frac{1}{2}$ and $\pi^{C}=1 /(1+\Lambda)$ into (5) and (6) to obtain $\theta_{h}^{S}$ and $\theta_{h}^{C}$ respectively, re-arranging and simplifying, it follows that

$$
S\left(\pi^{S}\right)-S\left(\pi^{C}\right) \gtreqless 0 \Longleftrightarrow 4\left(\gamma_{h}+\gamma_{w}\right)(\Lambda-1)+\mu_{h}(\Lambda+3) \lesseqgtr \mu_{w}(3 \Lambda+1)
$$

Hence, it follows that there exists a critical value $\Lambda^{\prime}$ [which is stated in Proposition 4] such that $S\left(\pi^{S}\right)-S\left(\pi^{C}\right) \gtreqless 0 \Longleftrightarrow \Lambda \lesseqgtr \Lambda^{\prime}$. The proposition follows immediately. QED

\section{References}

[1] Allen, Douglas W., "What Does She See in Him?: The Effect of Sharing on the Choice of Spouse," Economic Inquiry, 30 (1992), 57-67.

[2] Aura, Saku, "Uncommitted Couples: Some Efficiency and Policy Implications of Marital Bargaining," Manuscript, University of Missouri-Columbia, 2003.

[3] Baker, George, Robert Gibbons and Kevin J. Murphy, "Relational Contracts and the Theory of the Firm," Quarterly Journal of Economics, 33 (2002), 39-84. 
[4] Becker, Gary S., A Treatise on the Family (Cambridge, MA: Harvard University Press, 1991).

[5] Besley, Timothy, and Maitreesh Ghatak, "Government versus Private Ownership of Public Goods," Quarterly Journal of Economics, 116 (2001), 1443-1472.

[6] Chiu, Stephen Y., "Noncooperative Bargaining, Hostages, and Optimal Asset Ownership," American Economic Review, 86 (1998), 882-901.

[7] Chiappori, Pierre-André, "Collective Labor Supply and Welfare," Journal of Political Economy, 100 (1992), 437-467.

[8] Chiappori, Pierre-André, Bernard Fortin and Guy Lacroix, "Marriage Market, Divorce Legislation, and Household Labor Supply," Journal of Political Economy, 110 (2002), 37-72.

[9] Clark, Simon, "Law, Property, and Marital Dissolution," Economic Journal, 109 (1999), C41-C54.

[10] Coase, Ronald H., "The Problem of Social Cost," Journal of Law and Economics, 3 (1960), 1-44.

[11] Cohen, Lloyd, "Marriage, Divorce, and Quasi Rents; Or, 'I Gave Him the Best Years of My Life'," Journal of Legal Studies, 16 (1987), 267-304.

[12] De Meza, David, and Ben Lockwood, "Does Ownership Always Motivate Managers? Outside Options and the Property Rights Theory of the Firm," Quarterly Journal of Economics, 113 (1998), 361-386.

[13] Francesconi, Marco, and Abhinay Muthoo, "An Economic Model of Child Custody," Manuscript, University of Essex, 2004.

[14] Gray, Jeffrey S., "Divorce-Law Changes, Household Bargaining, and Married Women's Labor Supply," American Economic Review, 88 (1998), 628-642.

[15] Grossman, Sanford J., and Oliver D. Hart, "The Costs and Benefits of Ownership: A Theory of Vertical and Lateral Integration," Journal of Political Economy, 94 (1986), 691-719.

[16] Halonen, Maja, "Reputation and the Allocation of Ownership," The Economic Journal, 112 (2002), 539-558.

[17] Hart, Oliver, and John Moore, "Property Rights and the Nature of the Firm," Journal of Political Economy, 98 (1990), 1119-1158.

[18] Konrad, Kai A., and Kjell E. Lommerud, "The Bargaining Family Revisited," Canadian Journal of Economics, 33 (2000), 471-487. 
[19] Lommerud, Kjell E., "Marital Division of Labor with Risk of Divorce: The Role of 'Voice Enforcement of Contracts," Journal of Labor Economics, 7 (1989), 113-127.

[20] Lundberg, Shelly, "Limits to Specialization: Family Policy and Economic Efficiency," Manuscript, University of Washington, 2002.

[21] Lundberg, Shelly, and Robert A. Pollak, "Efficiency in Marriage," National Bureau of Economic Research Working Paper No. 8642., 2001.

[22] Manser, Marilyn, and Murray Brown, "Marriage and Household Decision Theory-A Bargaining Analysis," International Economic Review, 21 (1980), $21-34$.

[23] Marston, Allison A., "Planning for Love: The Politics of Prenuptial Agreements," Stanford Law Review, 49 (1997), 887-916.

[24] McElroy, Marjorie, and Mary Horney, "Nash-Bargained Decisions: Toward a Generalization of Demand Theory," International Economic Review, 22 (1981), 333-349.

[25] McLellan, David, "Contract Marriage - The Way Forward or Dead End?," Journal of Law and Society, 23 (1996), 234-246.

[26] Mnookin, Robert H., and Lewis Kornhauser, "Bargaining in the Shadow of the Law: the Case of Divorce," Yale Law Journal, 88 (1979), 950-997.

[27] Muthoo, Abhinay, Bargaining Theory with Applications (Cambridge: Cambridge University Press, 1999).

[28] Nöldeke, Georg, and Klaus M. Schmidt, "Sequential Investments and Option to Own," RAND Journal of Economics, 29 (2000), 633-653.

[29] Noack, Turid, "Cohabitation in Norway: An Accepted and Gradually more Regulated Way of Living," International Journal of Law, Policy and the Family, 15 (2001), 102-117.

[30] Peters, Elizabeth H., "Marriage and Divorce: Informational Constraints and Private Contracting," American Economic Review, 76 (1986), 437-454.

[31] Rainer, Helmut, "Should We Write Prenuptial Contracts?," Essex Economics Working Paper Series No. 572, 2003.

[32] Rajan, Raghuram, and Luigi Zingales, "Power in a Theory of the Firm", Quarterly Journal of Economics, 113 (1998), 387-432.

[33] Rasul, Imran, "Household Bargaining over Fertility: Theory and Evidence from Malaysia," typescript, London School of Economics, 2001. 
[34] Rasul, Imran, "The Economics of Child Custody," typescript, University of Chicago, 2003.

[35] Smith, Ian, "The Law and Economics of Marriage Contracts," Journal of Economic Surveys, 17 (2003), 201-225.

[36] Spier, Kathryn E., "Incomplete Contracts and Signalling," Rand Journal of Economics, 23 (1992), 432-443.

[37] Tee, Louise, "Division of Property upon Relationship Breakdown," in Jonathan Herring (ed.), Family Law: Issues, Debates, Policy (Cullompton: Willan Publishing, 2001).

[38] Weiss, Yoram, and Robert J. Willis, "Children as Collective Goods and Divorce Settlements," Journal of Labor Economics, 3 (1985), 268-292.

[39] Weitzman, Leonore, The Divorce Revolution: The Unexpected Social and Economic Consequences for Women and Children in America. (New York: Free Press, 1985). 